\title{
Dynamic simulation of first pass myocardial perfusion MR with a novel perfusion phantom
}

\author{
Amedeo Chiribiri ${ }^{1 *}$, Andreas Schuster ${ }^{1}$, Masaki Ishida ${ }^{1}$, Gilion Hautvast ${ }^{2}$, Niloufar Z Nooralipour ${ }^{1}$, Matthias Paull, \\ Shazia Hussain ${ }^{3}$, Philip Batchelor ${ }^{4}$, Marcel Breeuwer ${ }^{5}$, Tobias Schaeffter ${ }^{1}$, Eike Nagel ${ }^{1}$
}

From 2011 SCMR/Euro CMR Joint Scientific Sessions

Nice, France. 3-6 February 2011

\section{Objective}

To describe a novel hardware MR-perfusion phantom to model first-pass of a bolus of contrast in the cardiac cavities and large thoracic vessels (arterial input function, AIF) and in the myocardium, allowing for the acquisition of dynamic first-pass MR-perfusion data and for a precise control of cardiac output and myocardial perfusion for true validation of perfusion quantification.

\section{Background}

Development of quantitative MR-perfusion would benefit from the availability of a MR-compatible harware phantom allowing for a realistic simulation of the AIF and of the myocardial signal intensity curves. So far, mathematical phantoms or static samples with different $\mathrm{T} 1$ values have been described and a tool for development and true validation of MR-perfusion is lacking.

\section{Methods}

Our MR-compatible phantom resembles the anatomy of the heart and of the thoracic vessels of a $60 \mathrm{~kg}$ subject. Water flow $(2-41 / \mathrm{min})$ is driven into the system by a pump located outside the MR room. Gadolinium injections (Gadovist, gadobutrol, Bayer Schering, Germany) are performed in the vena cava by a power-injector (Medrad Solaris, Germany). Progressive dilution of the Gadolinium bolus across the chambers generates the AIF. A fraction of the cardiac output perfuses two myocardial compartments (made by arrays of parallel tubes) where perfusion can be controlled precisely and independently. Outside the MR room, a control unit allows for precise measurement and control of cardiac output and myocardial perfusion. The phantom was tested in a
3T-scanner (Philips Achieva, Netherlands). Acquisition of the perfusion sequence was repeated multiple times with a k-t SENSE sequence (flip-angle $=20^{\circ}$; TR $2.2 \mathrm{~ms}$; TE1.1 ms; k-t factor 5, 11 training profiles) using similar flow conditions to demonstrate the reproducibility of the measurements. Different flow conditions were used to assess the response of the system to different myocardial perfusion rates. Quantification was performed by Fermi deconvolution.

\section{Results}

The system produced realistic dynamic first-pass perfusion data (Figure 1A) and reacted very sensitively on alterations of perfusion-rate (Figure 1B). The phantom generated highly reproducible signal-intensity curves for similar flow conditions (Figure 1C and Table 1).

\section{Conclusions}

This novel hardware perfusion phantom allows reliable, reproducible and efficient simulation of myocardial perfusion. The availability of a direct comparison between the image data and reference values of flow and perfusion will allow for rapid development and validation of accurate quantification methods.

\footnotetext{
Author details

${ }^{1}$ King's College London, Wellcome Trust - EPSRC Centre of Excellence in Medical Engineering, London, UK. ${ }^{2}$ Philips Healthcare, Imaging Systems - MR, Best, Netherlands. ${ }^{3}$ King's College London, NIHR Biomedical Research Centre, London, UK. ${ }^{4}$ King's College London, Division of Imaging Sciences, London, UK. ${ }^{5}$ Philips Healthcare, PCCI Clinical Science \& Advanced Development and Eindhoven University, Eindhoven, Netherlands.
}

Published: 2 February 2011

'King's College London, Wellcome Trust - EPSRC Centre of Excellence in

Medical Engineering, London, UK

Full list of author information is available at the end of the article

(c) 2011 Chiribiri et al; licensee BioMed Central Ltd. This is an open access article distributed under the terms of the Creative Commons Attribution License (http://creativecommons.org/licenses/by/2.0), which permits unrestricted use, distribution, and reproduction in any medium, provided the original work is properly cited. 

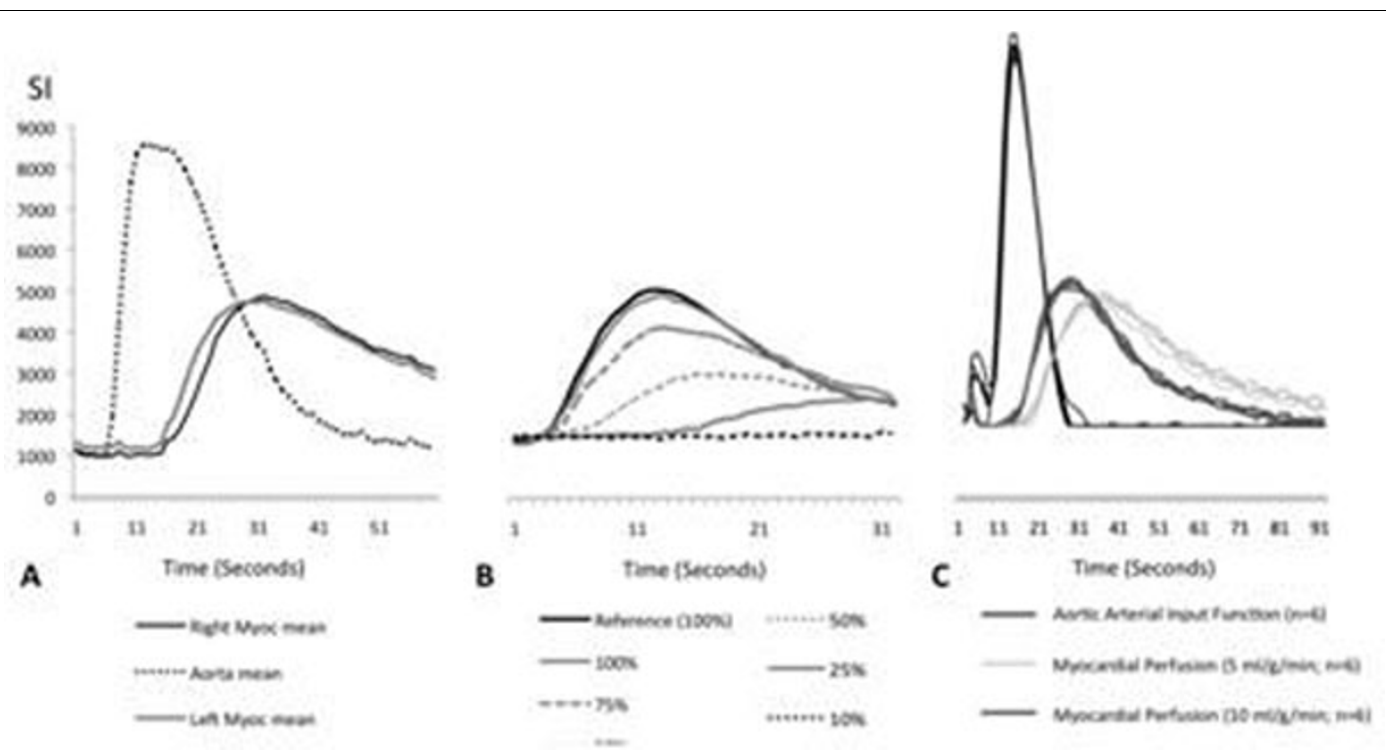

Figure 1 A. Arterial function in the aorta and signal-intensity (SI) in the right and left myocardial compartments (myocardial perfusion rate 10ml/ $\mathrm{g} / \mathrm{min}$; cardiac output $3 \mathrm{l} / \mathrm{min})$. B Dynamic response of the system to different myocardial perfusion rates $(10,7.5,5,2.5,1 \mathrm{ml} / \mathrm{g} / \mathrm{min}$, corresponding to $100 \%, 75 \%, 50 \%, 25 \%$ and $10 \%$ of the reference). C. Reproducibility of the measurements for constant values of myocardial perfusion rates (5 and $10 \mathrm{ml} / \mathrm{g} / \mathrm{min}$ ) and AIF (with a cardiac output of $4 \mathrm{l} / \mathrm{min}$ ).

Table 1 Experimental conditions and calculated myocardial perfusion rates (Fermi deconvolution) for the dynamic test and the reproducibility test represented in Figure 2 B and $C$ respectively

\begin{tabular}{lll}
\hline & Dynamic response test & Reproduciblity test (n=6) \\
\hline Cardiac output (I/min) & $3 \mathrm{l} / \mathrm{min}$ & $4 \mathrm{l} / \mathrm{min}$ \\
Right myocardial perfusion & $10-7.5-5-2.5-1 \mathrm{ml} / \mathrm{g} / \mathrm{min}$ & $5 \mathrm{ml} / \mathrm{g} / \mathrm{min}$ \\
Fermi deconvolution results - Right myocardial perfusion & $9.8,6.4,4.0,2.0,0.9 \mathrm{ml} / \mathrm{g} / \mathrm{min}$, respectively & $5.5 \pm 0.2 \mathrm{ml} / \mathrm{g} / \mathrm{min}$ \\
Left myocardial perfusion & $10 \mathrm{ml} / \mathrm{g} / \mathrm{min}$ & $10 \mathrm{ml} / \mathrm{g} / \mathrm{min}$ \\
Fermi deconvolution results - Left myocardial perfusion & $10.8 \mathrm{ml} / \mathrm{g} / \mathrm{min}$ & $9.5 \pm 0.2 \mathrm{ml} / \mathrm{g} / \mathrm{min}$ \\
Injected Gadobutrol volume & $0.6 \mathrm{ml}$ & $0.6 \mathrm{ml}$ \\
Speed of Gd injection (ml/s) followed by $20 \mathrm{ml}$ of saline & $4 \mathrm{ml} / \mathrm{s}$ & $4 \mathrm{ml} / \mathrm{s}$ \\
\hline
\end{tabular}

Submit your next manuscript to BioMed Central and take full advantage of:

- Convenient online submission

- Thorough peer review

- No space constraints or color figure charges

- Immediate publication on acceptance

- Inclusion in PubMed, CAS, Scopus and Google Scholar

- Research which is freely available for redistribution 